Article

\title{
Local Notions of Alternative Practices: Organic Food Movements in Bangkok, Thailand and Chennai, India
}

\author{
Judith Bopp \\ Department of Geography, Kiel University, Ludewig-Meyn-Str. 14, 24098 Kiel, Germany; \\ bopp@geographie.uni-kiel.de; Tel.: +49-431-880-3429
}

Received: 27 January 2020; Accepted: 27 February 2020; Published: 4 March 2020

check for updates

\begin{abstract}
I argue that the common discourses on alternative practices often entail a Western perspective and are sometimes treated as new paths of thinking. This also applies to alternative food practices such as organic farming. Based on empirical research on organic food movements in Bangkok and Chennai, I suggest two examples of alternative practices that have become naturally incorporated in daily routines. Through qualitative expert interviews, long-term observation, and action research, the study reveals that in these movements, urbanites advocate for the right to healthy foods and solidarity with rural farmers, and that farmers employ local sustainable farming methods, including careful resource management and agricultural diversity. Stakeholder engagement is long-term and embraces a spiritual-cultural tone of alternativeness. Based on my findings from my case studies, I propose the following two recommendations. First, the alternative practice discourse needs to open up to the existing plurality of perspectives-openness may prevent the alternative practice discourse from overlooking notable sources of inspiration from societies that inherently perform a diversity of sustainable agricultural practices. Second, continuity, local sustainability notions, and mindfulness need to be included as criteria in the debate. The incorporation of these three themes represented by my two case studies may enrich the discourse through a more local, Global South perspective on alternativeness, and advance its conceptualization.
\end{abstract}

Keywords: alternative practices discourse; local sustainability notions; organic food movements; agricultural diversity; Global South perspective; Bangkok; Chennai

\section{Introduction}

Alternative practices are understood as sets of handling individuals' or communal routines, codes, and knowledge with the intention to draw away from the mainstream. In the field of economic geography, alternative practices are studied under the aspect of "non-capitalist economic forms such as cooperatives, informal livelihood strategies, or unpaid labor" [1]. The discourse on alternative practices mainly features contributions from the Anglo-American and European contexts, but practices are context-specific and the discourse requires the inclusion of perspectives from other cultural spheres [2-7]. A significant body of academic literature addresses alternative food networks as a subcategory of alternative practices. These represent 'organized flows of food products that connect people who are concerned about the morals of their consumption practices' [8] (p. 383) and are often orientated at food production and procurement schemes countering the conventional system [5] (p. 9), [6] (p. 378). Research has produced a range of alternative food network typologies [5,6], and has examined those networks for their exclusiveness, for instance based on race or class [9-11]. Many studies also examined the supply chain in alternative food networks [4,12]. Goodman et al. [13] dedicate a chapter to the globalizing impulse of fair trade, but otherwise maintain the perspective of the UK, Western Europe, and the USA on alternative food networks. 
In contrast, argumentation rooted in case studies from the Global South is widely absent from the discourse; the same is true for the moral values and personal motivations that impel stakeholders to engage in alternative practices [5] (p. 9), while the eco-psychological discourse for instance has brought in those perspectives [14]. A closer look at individuals' motivations and preferences, however, is important in order to grasp alternative practices in all their dimensions.

In Bangkok, an organic food movement has been gaining new momentum for about a decade. In this movement, a wide range of stakeholders, mostly from civil society, engages to lobby for organic foods for reasons of health, environmental concern, and personal lifestyle, which is what public policies yet fail to address. The organic movement equally addresses solidarity with rural producers who counter mainstream agriculture by using sustainable farming methods that draw upon traditional farming knowledge. Stakeholder engagement is both new and continuous, since it recalls NGO activity that started in the 1980s in the context of rural development and consumer-producer cooperation.

Meanwhile, in the urban spheres, stakeholders from different social backgrounds engage in the movement in a bottom-up nature, gathering like-minded concerned consumers, social entrepreneurs, NGOs, private activists, as well as rural organic farmers. Despite explicit heterogeneity, those scenes connect via a shared ideology rather than by any intention to follow a trend. The rural and the urban spheres closely interlink in this movement, and stakeholders embrace rural practices and memories. These span traditional food, farming, health care, simple village-style living, and community-based economies such as producer-consumer schemes or bartering, to name a few. The stakeholders' motivations are often framed by mindfulness: they address both the individual dimension of personal health and well-being and the community dimension through care for farmers' livelihoods and the urban neighborhood.

Similar scenes occur in Chennai: a range of private stakeholders maintain organic kitchen gardens and peri-urban farms, along with water and waste recycling practices; NGOs and public institutions run campaigns for food safety, farmers' rights, and school gardens; young individuals join back-to-the-land movements. Just as in Bangkok, interest for organically grown products is rising for reasons of health and social-environmental concerns, since the contamination of conventional foods together with trends of unhealthy eating habits anticipate a public health crisis. There is also an ambition to support struggling rural farmers, and organic agriculture appears as a possible livelihood strategy for peri-urban smallholders in opposition to widespread industrial farming.

This is how Bangkok's and Chennai's organic scenes constitute similar settings, and the stakeholders in both regions realize what the common discourse means for alternative practice, yet without naming it as such. Instead, stakeholders pursue alternative practices according to their own local sustainability notions. These practices notably derive from local food and farming knowledge through the continuous transfer or recent recollection of the practices of previous generations, and thus, realize a diversity of agricultural practices. These encompass natural farming techniques, traditional knowledge on soil improvement and resource management, and sensitivity to social-ecological soundness.

The two case studies take into account a food-related perspective on alternative practices, namely 'alternative food practices' to do with 'how people eat, farm, and purchase food and to promote human and nonhuman wellbeing, social justice, and the economic viability of places' [11] (p. 520). In line with Batat et al. [15] (p. 565), they suggest the 'idea of alternative as meaning shaped by reference to the ideology of a particular sociocultural context'. I argue that research on alternative practices lacks plurality because of its focus on case studies from 'Western' regions. An understanding of the values, practices, and knowledge systems which food often relates to in 'non-Western' spheres could provide inspiration for both private households and policy makers globally for practical implementation of sustainability practices, but this understanding is lacking in the common alternative practice discourse. The hegemonic discourse can benefit from openness to the Global South perspective through the (re)generation of valid local knowledge and sustainability practices from existing sources: 'non-Western knowledge traditions and cultural practices are all to be considered as potential sources of social science theories and concepts' [16] (p. 1). Increased attention to the individual and to the cultural-spiritual 
dimension in food practices can give rise to holistic, value-based research and eventually engender a more global impact of food practice-related research.

This paper stems from empirical research in Bangkok and Chennai dealing with the local organic food movements, stakeholder motivations, and small-holder livelihoods and is based on mainly qualitative methods of social sciences combined with ethnographic elements, such as interview, informal discussion, and observation that is partly participative. Consequently, the objective of this paper is to present local notions of alternative practice as revealed through the two case studies. For the understanding of local notions of what Western academics discuss as alternative practice, I will stress three aspects apparent in both case studies: continuity of practice, sustainability notions, and mindfulness. Notably, the case studies demonstrate the existence of alternative food practices that come with elaborated and adapted sustainability strategies. These naturally grown sustainability notions include a diversity of agricultural practices including natural farming techniques, traditional knowledge on soil improvement and resource management, and sensitivity to social-ecological soundness.

Section 2 of this paper begins by outlining the current discourse on alternative practices and their characteristics. (Stakeholders in the case studies presented in this paper embrace agricultural diversity; however, the latter is not covered by additional literature in order to keep the focus on the alternative practices literature.) I then present my case studies and my employed research methodology in Section 3, before analyzing the studies regarding the three main themes of continuity, sustainability notions, and mindfulness in Section 4. I will sum up in Section 5 to draw conclusions on the local notions of alternative practices in the organic food movements in my two studies, and will give further reflections in Section 6.

\section{Current Alternative Practice Discourses}

The discourse on alternative practices pushes human geography to expand in subfields like economic and cultural geography, and geographies of food in particular (for example $[17,18])$. Therein, they appear as alternative economies [19], often termed 'diverse economies or livelihoods' [1], or as alternative food practices $[3,10]$ or networks $[5,6,20]$.

Research on alternative practices is interdisciplinary. Its discourse borrows from classical approaches to practice: for example, Bourdieu in whose eyes practices 'reflect the dispositions or subconscious understandings of the world' [1] (p. 10) and the individual situated in social class or the socio-cultural setting; Foucault, whose concern is about the employment of ideologically constructed practice as a 'structural tool' [1] (p. 10) of the state; and de Certeau, seeing everyday practices 'as tactical compromises between an individual's need to conform to the dominant social order and her/his personal expression of identity, meaning, and values' [1] (p. 11).

Hillebrand and Zademach [21] discern 'alternative modes to the organization of social and economic interaction around the globe' that 'give occasion for rethinking the economic system in itself' (p. 9). Sociologist Castells brings up the 'rise of alternative economic cultures' as a form of protest against capitalism and the growing digital culture [22]. He speaks of 'consumers who cannot consume', and therefore 'make sense of their lives doing something different $[\ldots$ ] because of needs and because of values' [22]. Saying that, he thinks of economic practices beyond 'for-profit motivation-such as barter networks; such as social currencies; co-operatives; self-management; agricultural networks; helping each other simply in terms of wanting to be together' [22]. Daya and Authar [23] (p. 886) equally point out globalized neoliberal capitalism as a 'point of origin for many studies of alternative economies'.

These comments reflect a growing interest in modes of exchange beyond the mainstream capitalist system and allude analogously to ways of living in more value-based relationships. These modes also imply systems of food provisioning [8] (p. 383).

Sánchez Hernández [6] (p. 376) allows for insight regarding alternative food networks as 'channels of food production, distribution, and consumption, which are built upon [ ... ] close communication between producer, produce and consumer'. 
Those definitions also apply to my case studies, but put the focus on food produce as a tangible value of food networks. It corresponds to the first of two general observations on the research literature on alternative food practices: many of the empirical and theoretical contributions are 'rooted at the production end of the food chain' [5] (p. 2). This, as I claim, simplifies alternative food practices by giving prominence to their material representations. In my view, food provisioning includes, besides food chains and networks, an array of philosophies and cultures around the growing and consuming of food, such as the cultivation of soils, the handling of and relationship to natural resources, or the maintenance of agricultural diversity and food cultures. The second observation is that studies are widely empirical and theoretical framing remains limited.

\subsection{Hegemonic Discourses}

In discussions with academic colleagues on alternative food practices and in the context on the organic food movements in Bangkok or Chennai, I noticed that the subjects of organic food and sustainable farming methods in Thailand and India and in 'developing countries' in general was approached with skepticism. (Discussions of this kind occurred for instance at the 5th Global Conference on Economic Geography 2018 and discussions with fellow academics throughout my research.) Yet, counter-movements to capitalist practice exist throughout the world, as they are co-products of globalized lifestyles [22]; they consequently also apply to societies in the 'Global South'. It may be argued that these discussions reflect the belief that Western societies are leaders in both development and alternatives. It seems as if developing countries needed to go through the stage of uncritical capitalism, consumerism, and modernisation before conceiving to change track towards counter-movements.

The alternative practice discourse becomes explicit about the 'need to move (European) [alternative food networks] beyond the niche' for their 'transformative and progressive role' [8] (p. 387). Sassatelli [24] (p. 181) identifies alternative consumption as 'stretching across the developed world', to name two examples of centrism.

\subsection{Towards a Pluralistic Framework}

One bias of this centrism lies in looking 'at other societies within a Western paradigm' [25] (p. xiv). The hegemonic discourse reflects 'continuities in imagined geographies' [26] (p. 4), persisting in projecting the 'Western experience' onto the perception of non-Western spaces [27], a tendency that has already been affirmed in earlier development discourses (for example [28] (p. 100). For a fruitful comprehensive discussion on a global scale, this centrism needs to be overcome. This resonates with Alatas [16] (p. 4), who outlines the 'contribution of non-Western systems of thought to theories and ideas' in alternative social sciences discourses in general. He expresses what may be suggested here as a prerequisite for the alternative practice discourse, too, namely 'the turn to indigenous philosophies, epistemologies, histories, art and other modes of knowledge, which are all potential sources' [16] (p. 4).

Viewing the research literature on alternative practices brings me to suppose that general traits and characterisations of alternative practices as drawn from the discourse (see Section 2) resemble my own findings from Bangkok and Chennai. In contrast, the discourse often approaches alternative food practices from an economic- and produce-orientated view or through cases that attend to concrete alternative experiments. I argue, this elaboration is expandable for consumer and producer motivations and cultural values equally determine those practices. I further regard alternative food practices context-specific: The Anglo-American and European angles may not aptly apply to other cultures and the 'alternative content of some food practices may be a matter of deep discussion from other cultural realms' [6] (p. 376).

In the following, I present two case studies from Bangkok and Chennai that challenge the currently hegemonic discourse which represents mostly empirical results from Western settings and theorization through Western models. (The hegemony also lies in assumption of what is mainstream and what is alternative, and in my case studies, the alternative as described in the common discourse 
is to a great extent not the alternative, but local sustainability practices that have never been lost.) They attempt a holistic view of practices and the stakeholders involved in these, capturing their motivations, understandings of sustainability, and embeddedness in local morals and values, while their intention is not to display contrasts to Western case studies. By demonstrating comprehensiveness in terms of a sustained and organically grown set of local practices spanning several dimensions of food-production, consumption, exchanging, preparation, nature, and spirituality-the case studies are a complement to the discourse and open a new, more global discourse of alternative food practice.

\section{Situating the Organic Movements in Bangkok and Chennai}

Data collection in Bangkok extended over three periods between February 2013 and May 2016, including thesis editing. Extended fieldwork facilitated repeated meetings with a range of stakeholders and continuous revision of study objectives. In Chennai, a nine-month stay at the Indian Institute of Technology Madras in 2017 covered an initial phase of fieldwork and was followed by a second phase in February to April 2019 with a different focus. The selection of case studies followed both pragmatic reasons and personal interest: Bangkok was chosen for academic affiliations in the region and the integration of the study in megacity research, Chennai for the existing exchange program and the ambition to do comparative research in further Asian regions.

\subsection{Material and Methods}

Both sites were approached by a set of mainly qualitative methods including observation, partly participative, open expert interviews, informal discussions, farm excursions and attendance of workshops, fairs, and markets. The openness of the interviews varied according to the participants: More standardization was considered with the consumer interviews [29] (p. 35/36). The studies covered experts differently involved in the organic scenes in order to embrace multiple perspectives on the topic. They included, for example, practicing farmers and urban gardeners, organic consumers, retailers, trustees of NGOs or associations, and governmental officials (see Table 2). Many of the experts were approached via recommendation through existing networks. In Bangkok, a survey of organic food consumers and secondary data from Thai agricultural statistics and health reports were added [30] (p. 19). In Chennai, I undertook an additional action research by co-conducting weekly school gardening sessions (see Table 1).

Those tools were chosen to cover both a stakeholder reality, consisting of their personal motivations of engagement, lifestyle ambitions and identity, and a situational reality, consisting of a socio-political and agricultural setting, farmers' livelihoods, farming methods, and public health. The combination of both reflects the epistemological idea of reconciling multiple, socially constructed and subjectively perceived realities with the occurrences observable through the researcher's senses [29] (p. 75/76), [31]. The study in Chennai had a second focus on collecting local organic farming knowledge.

As for the theoretical framework, the study in Bangkok was in the main viewed through new social movements (for example [32-35]) and the voluntary simplicity approach [14], as well as concepts of sustainable farming and urban gardening. The study in Chennai was started without a prior literature review and aims at eventual theorization according to grounded theory approaches $[36,37]$ (see Table 1). 
Table 1. Material and methods of case studies.

\begin{tabular}{ccc}
\hline & Bangkok & Chennai \\
\hline Methodology & Qualitative: fieldwork, document analysis & Qualitative: fieldwork, parallel document analysis \\
\hline \multirow{4}{*}{ Tools } & Observation: 3 periods, 30 months & Observation: 2 period, 11 months \\
& 43 expert interviews & 29 expert interviews \\
& 25 consumer interviews & Informal discussions \\
& Informal discussions & Farm excursions \\
& Farm excursions & Secondary data \\
Literature review & Action research: school gardening sessionsLiterature review \\
\hline \multirow{2}{*}{ Theorization } & 2 Grative study peri-urban Chennai \\
& New social movements, voluntary & Inductive \\
& simplicity, identity, personal lifestyles & \\
\hline
\end{tabular}

Expert interviews were mostly audio-recorded and transcribed using verbatim transcription. The interviews were conducted in English and the transcripts have not been edited. Other data was documented through notes and photographs. Topical coding according to core themes was employed for data analysis. Direct quotations from the various study participants in Bangkok and in Chennai that follow in this paper were extracted from respective interview transcripts.

\subsection{The Stakeholders in the Organic Movements in Bangkok and Chennai}

In Bangkok, the organic food movement unfolds a multi-layered nature, mirroring structural factors (the complexity of rural farmers' livelihoods, food pollution, environmental degradation in rural and urban places, agricultural policies), and factors on the stakeholder level (individual motivations and lifestyle aspirations, NGO intervention, business interests). Sub-scenes of the movement connect via their shared ideologies and challenge the conventional food and agricultural system in a bottom-up manner, some unintentionally. While these stakeholders act for the right to nutritional healthy food in the city, governmental bodies act hesitantly.

A wide range of stakeholders give impulse to organic farming, organic food markets and networks, consumer awareness, and simple urban living through their continuous engagement, among them several notable pioneers, as well as private households, public and semi-public bodies, NGOs, educational institutions, and private social enterprises. Table 2 summarizes stakeholders covered by both of the case studies and extracted from the interviews according to the categories they apply to:

Table 2. Stakeholders in Bangkok and Chennai's organic food movement according to categories.

\begin{tabular}{|c|c|c|c|}
\hline Household & Public / Institutional & Enterprise & Network \\
\hline
\end{tabular}

The individual stakeholders in Bangkok are equally diverse: in spite of the notable involvement of the middle classes, different social backgrounds are represented, and gender and age specification are irrelevant. For instance, the Cityfarm network spans both low income communities and households with stable economic backgrounds. In contrast, their motivations rather uniformly center around personal and family health and well-being, as well as care for others' health, which is often cited by organic producers. Ecological consciousness is named as a second motivation. 
Although typification is difficult, a relatively recent stakeholder group is that of young academics with well-paid office jobs brought up in Bangkok who become involved in urban farming or leave the city in favor of starting organic farms.

The study found that stakeholders, apart from a few who are involved in the organic scene because it is trendy, represent genuine commitment to the 'organic philosophy'; they aspire to a simple lifestyle and mindfulness in relation to their consumption and interaction with both their social and natural environment regardless of their economic status.

To conclude on the individual stakeholders involved, study participants characterize themselves as urbanites, rural farmers, families, young people, green consumers, office workers, stable salaried professionals, the middle classes, the urban poor, well-informed, conscious, and pro-active.

My fieldwork in Chennai comprised of an initial exploration of the organic food scene in 2017, and an explorative study and mapping of peri-urban agriculture and a study of rural organic farming projects in 2019. It allowed for following the insight: the local organic food movement resembles the one in Bangkok with comparable stakeholders equally motivated by health and environmental concerns (see Table 2).

Similarly to the Thai case, Indian agriculture is in a state of ongoing crisis, manifesting itself in farmers' precarious livelihoods, the degradation of arable soils and of water and crop variety, and the encroachment of non-farming activity into the rural spheres [38]. Almost all farmers in interviews named a scarcity of irrigation water as a pressing issue next to that of eroded soils, and many stated farmers' deteriorating health. The green revolution implementation is often quoted as one reason for this negative trend. 'While the green revolution led to an immediate increase in production and productivity of agriculture, it was achieved at a heavy cost to the environment and is not a sustainable long-term strategy' [38].

Fieldwork in Chennai also allowed for conclusions on business-orientated stakeholders who target the organic scene. Also, farmers often mentioned economic improvement as their main motivation other than health. One notable insight is that several farm owners interviewed do not cultivate their land by their own hands but employ farm workers. This hints at class bias in stakeholder motivations in the Chennai case: many small-holders see organic farming as a necessary, although risky, step towards livelihood improvement, whereas land owners often do not depend on their produce and can afford to experiment with different farming methods.

Unlike stakeholders in Bangkok, those in Chennai do not explicitly mention the aspect of mindfulness, but do mention the importance of humans' link to nature. Also, stakeholders found local farming knowledge to be very important in the transfer of organic practice.

Notably, both case studies are examples of regions where spirituality harmonizes with agricultural practice to a great extent, and where prevailing cultural values combined with the inherent urges for alternative food and farming practices engender typical sustainability notions. Agricultural diversity in terms of locally adapted farming systems that include organic inputs, biodiversity, heirloom seeds, adapted scale and resource management, and local knowledge are inherent to these sustainability notions.

Spiritual philosophies in agricultural practices are not exclusive to non-Western spheres, however, the case studies remarkably revealed them.

\section{Analyzing the Organic Food Movements in Bangkok and Chennai}

As referred to in Section 3, the organic movements in both of my case studies seek to manifest the right to nutritional food; the aspiration for personal health, well-being and mindful living; as well as solidarity with rural food producers. The organic stakeholders thereby express lifestyle choices that differ from the prevalent practice and challenge the current food and agricultural systems. Their choices reflect an intentional opposition to the mainstream for some, while others act rather passively since they internalize alternative practices naturally in their personal attitudes. For many of the organic 
stakeholders, the organic food practices ultimately relate to local food cultures. The preservation of organic food practices therefore contributes to regional cultural preservation.

For reasons of socio-cultural diversity, the organic food movements in Bangkok and Chennai should be differentiated. However, against the hegemonic 'Western' discourse, both examples add to acknowledgment of the existence of alternative food practices in the 'Global South', their sustained and inherent realization showing that they are not new. This shall be further elaborated with regards to the three themes extracted from the case studies.

\subsection{The Continuity and Re-emergence of the Movement}

The organic food movement in Bangkok has gained momentum recently while having its origin in the rural spheres of the 1980s when local NGOs for rural development along with individual pioneers sought to revive the traditional farming methods that were sensitive to the local environments and farmers' self-reliance (see Section 1). Although the industrialization of agriculture had made insertion in these regions, the traditional approaches were still available:

'around 30 years ago, we found the very intelligence farmer in the rural area that they can create their own concept about the integrated farming' (interview, organic urban gardening pioneer, Bangkok).

Practitioners reported the traditional farming method is inherently small-scale, diverse in agricultural crop varieties, chemical-free, and can be considered 'organic'; they often referred to it as going beyond organic, due to the local paradigmatic conception of organic farming as the entrepreneurial and industrialized branch of chemical-free farming. The achievements of the green revolution since the 1960s proved to be unsustainable, initiating a loss of local varieties in favor of hybrid crops and farmers' withdrawal from traditional farming methods.

The movement has since experienced several waves of impulse: In effect, past structural state crises repeatedly triggered a reemphasis on organic food, with a recent one from the late 2000s onwards. More recently, an agricultural crisis has affected farmers:

'They have a lot of debts. They are very poor health and they is no hope in the future' (interview, organic pioneer and NGO member, Bangkok).

The study participant continues to explain:

'Because they don't get [ ... ] any benefit from the green revolution. Even the high yield, they can grow two or three times per year, but the input is a lot. They must buy everything' (interview, organic pioneer and NGO member, Bangkok).

In Thailand, this reality is associated with a stark increase in prices for chemical fertilizers, while the commodity value of rice remained low.

There is also a public health crisis, with food products on the regular market repeatedly testing positive for chemical or heavy metal residues, antibiotics or hormones. An increase in non-communicable illnesses is believed to be caused by this food pollution, but it is also thought to be caused by a shift in eating habits towards a meat-based diet, which is lower in health benefits than the traditional local dishes $[39,40]$.

The evolution of the organic movement describes continuity, and its contemporary impulse is re-emergence rather than new emergence: the initial impulse for the organic food movement came from rural development intervention in the 1980s, and farmers recollected traditional farming methods and 'integrated farming' through locally available knowledge. The movement consequently grew in several waves, adapting to new stakeholder intentions and structural settings, while keeping the original intentions and ideologies. A similar structural setting was registered in Chennai's organic food scenes. 


\section{Embracing of Local Knowledge}

The insight that the alternative food practices in Bangkok and Chennai are not new can be illustrated by retracing their incorporation of local knowledge, as an integral part of local traditional food and farming practices, which have been employed by successive generations.

Study participants in Bangkok and Chennai referred to local farming knowledge as traditional, sometimes self-reliant, farming. Traditional farming largely relies on agricultural diversity and on farm-internal inputs, such as manure, indigenous microorganisms, and compost. It is small-scale, and hence allows for manual management, and cultivates a variety of edible and non-edible plants on agro-forestry schemes; on the output side, a variety of vegetables alternate with rice, pulses and oil seeds, allowing farmers to provide for the household as well as to donate or sell any surplus. Trees facilitate water retention and nutrient-building in the soil, as seen in both case studies. Bulls and buffaloes often help with the ploughing, and rainwater is collected for irrigation. Self-reliance also means a scale that is capable of sustaining the farmer's household, but is manageable without regular external labor.

While industrial farming using agro-chemicals for increased food security was only introduced in the green revolution about five decades ago, traditional farming methods, inherently ecologically sensitive, existed all along, which means that this 'kind of wisdom and knowledge is really still quite present' (interview, seed-saving activist, northern Thailand). Study participants allude to a knowledge gap grounded in inconsistent transfer of organic practices (field notes, agro-ecological farming expert, Bangkok), but it is generally found bridgeable in the sense of being retrievable within the organic farming community. It mostly circulates among the practitioners themselves and is often embedded in folk stories and even religious narration, according to several study participants in Chennai. The preservation of local wisdom thus receives cultural support.

Several institutions in the movement currently work on preserving local knowledge and agricultural diversity practice. In Bangkok, a sustainable agriculture foundation organizes an annual fair on alternative medicine derived from medicinal herbs and organic foods. In Chennai, farmers' seed-saving networks help sustain this knowledge, vehemently advocating its preservation, and equally a foundation for indigenous knowledge systems. My case study in Chennai revealed that local food and farming knowledge are still deeply anchored in the cultural practices inherent to the daily routines of many farmers who practice organically or who have shifted from conventional farming.

'A lot of it is also consistent with the sustainable agriculture [ ... ] because we use local knowledge' (interview, trustee of a foundation for indigenous knowledge, Chennai).

For instance using repellents made from the neem tree or fertilizers based on cow dung and urine. The quote also reflects the coincidence of traditional practices and sustainability in agriculture, lying in the long-term benefits for soils and resources on the one hand, and farmers' health and livelihood on the other, which participants in both case studies reported. Despite fading, this knowledge has in most cases not skipped generations, and for some young farmers who descend from farming families, traditional farming knowledge is still intuitive, hence they have 'that traditional instinct for farming' (interview, organic farmer, southern India). Much of this knowledge rests on a local science that deals with practices to prevent and cure plant diseases, so-called Vriksha Ayurveda.

This shows that the local knowledge continues through actual practice and imitation. In terms of knowledge preservation and transfer, study participants in Chennai in particular pointed to the oral rather than the written tradition: distribution happens via radio, television or itinerant narration by knowledgeable practitioners, reproducing first-hand farming experiences.

Accordingly, one of the study's findings was that the present activities of the organic scenes are not a new phenomenon: their recent momentum is, rather than a new emergence, a recollection of previous activities that had not been lost and that have their source in successively transferred local practices. It may be reasoned that the relatively short period of agricultural industrialization and the reality that 'the corporate system has never reached such an hegemony' [6] (p. 379) prevented local 
food and farming practices from completely fading, so that the knowledge of those practices persists to naturally challenge the mainstream food and farming system.

\subsection{Local Sustainability Notions}

Alternative food practices often challenge the general corporate food supply chain that 'detaches food from its social, historical, and geographical context' and substitutes natural food items with those from industrial production [6] (p. 375). Both movements in Bangkok and Chennai equally do this, but neither of them seem to claim alternativeness in their practice, neither the farmers nor the consumers. A reason might be that stakeholders in the movements refer to their own notions of sustainability through their personal lifestyle choices, and often those notions actually integrate into common practice: 'in India, sustainability and eco-friendliness are inherent to our knowledge systems' [38]. In Thailand, there is a precept of 'no harming, [which] you can extend [ ... ] to environmental', and temples sometimes have 'programs that try to preserve the environment and also teach people about that' (interview, organic social entrepreneur, Bangkok).

Sustainability implies the inclusion of a plurality of target groups with the aim of promoting organic farming and adequate livelihoods: the organic food movements in Bangkok and Chennai target the consumer and the producer in mutual support. Apart from direct consumer-producer links, local NGOs for rural development give technical and advisory support to farmers in conversion to organic farming, and a civil network draws attention to their struggles over land ownership, agrarian reform issues, and negotiation of fair market prices. A foundation for sustainable agriculture and community empowerment in Bangkok maintains inclusive activities, which they direct for example at low-income communities and at elderly and youth empowerment.

In the urban spheres, the sustainability notion goes towards urban greening and gardening, waste and water recycling and composting, as traditionally done, and thereby combining an ecological and economical component. For instance, it used to be common for urban households to have at least a few fruit trees, coconut trees, and herbs for kitchen use, and clean waste water from the households was used for watering, according to study participants in Chennai. It is typical in Bangkok to have orchards in people's gardens, as well as along the dense urban net of canals [41]. It is thus 'our traditional way of [ ... ] gardening around their house' wherever possible (interview, representative of Cityfarm group, Bangkok).

Other NGOs, as well as private stakeholders, put food safety campaigns and the advance of organic policies on their agenda as opposition against food corporations, which more and more encroach on the traditional food system.

Considering the increasing pollution of foods, access to healthy and sustainably produced foods is becoming a pressing issue and the reason for most urban farmers to cultivate their own food-more so than food security - and for farmers' markets and food cooperatives is to demonstrate independence from the regular market.

Regarding the local farming approaches, study participants in both case studies repeatedly stressed that organic farming was natural and self-evident practice before the green revolution reformed agricultural production - 'practices of [ ... ] our alternative way of farming' (interview, NGO expert for food safety, Bangkok) - yet under different names. Accordingly, the organic farming practice, particularly that of small-scale organic farmers, draws inspiration from local methods, as one organic pioneer in Bangkok outlined:

'We start from most of [the] farmers' — while organic farming scenes in other countries often began from initial concepts 'like a Biodynamic [ ... ] the lecturer, like Steiner' (interview, organic urban gardening pioneer, Bangkok).

This interviewee continues to explain how the organic approach-here using the term 'integrated farming' - preceded the conventional approach and then co-existed with it: 
'The first time is good because the yield is increased by using of the chemical inputs, but after that, around 20 years ago, we found that it's not good now', and eventually, 'some farmers in the remote area [ ... ] created their own integrated farming'. 'Integrate farming is [ ... ] our local wisdom, especially in Bangkok', where canals integrated with the land allow for efficient irrigation; therefore, 'we grew a lot of the mixed farming at that time [ ... ], for the Chinese people and the local Thai people, too'.

With the promotion of conventional farming in the course of the green revolution, the prevalent farming system substantially changed from mixed farming to monocropping, before the original approaches were eventually refashioned, and currently are promoted by the organic food movements. In the Chennai case study, several organic farmers in interviews stressed the multitude of benefits from mixed farming, for example, soil improvement, a harvest throughout the year, and hence a constant income.

Local integrated farming approaches, including self-reliance, connect the farming method to livelihood, thereby carrying ecological and social components. They may thus be seen as a local means to sustainability. Self-reliance implies that households can sustain themselves, which is facilitated by a manageable plot scale, and appears as a recommendation in both case studies. Industrial farming, in contrast, does not allow for self-reliance and is also not economical due to the dependence on external inputs, as smallholders explained. Although economic profit is preferred over self-reliance by many farmers nowadays, self-reliance can provide a personal sustainable livelihood, and in addition to that the possibility for exchange:

'And the surplus, we just give to another. [ ... ] We have enough for you' (interview, organic farming pioneer, Bangkok).

This, it may be argued, relates back to the moral incentive for alternative consumption [8] (p. 383) (see Section 1), which motivated many study participants, particularly in Bangkok's movement.

The organic food movements in Bangkok and Chennai show that local notions of sustainability exist, and as they have evolved from the local contexts and also co-existed along with more recent, imported practices such as industrial farming or 'globalized diets', they might differ from 'Western' sustainability approaches. For example, these local notions rooted in transferred knowledge and hence, do not need to be newly invented. These local sustainability notions may be further illuminated through specific attitudes and mindsets as follows.

\subsection{Mindfulness and Spirituality}

Alternative practices are cultural, and my case studies offered interesting insights into the organic food movements' strong links to mindfulness and spirituality.

Mindfulness is a concept that Bangkok's organic food scenes refer to as 'one's attentiveness to his or her environment', which appears 'in the context of mindful consumption', 'psychological motivations guiding individuals' engagement', and 'Buddhist practice' [39] (p. 14). Mindfulness and simple living are among the organic stakeholders' lifestyle aspirations, such as the urban gardeners for whom gardening has connotations of improved physical and psychological health. Thus, a number of organic stakeholders in Bangkok and Chennai choose to consume less, to buy sustainably produced products, to grow their own food, to recycle, to share harvest, seeds, and material and non-material goods, and to maintain consumer-producer links as a manifestation of anti-consumerism and mindful living-mindful referring to the care of one's environment.

My two case studies revealed the self-fulfillment that the organic stakeholder gains from realizing a mindful lifestyle, which may be considered a psychological need [14]. Study participants appreciated voluntary simple living for improving their physical and mental health and general life balance. An organic farming activist, referring to moderation and sharing with others, stated: 'This is go to your mind, your spirit. It's make you happy. Higher level, not just consume the material' (interview, organic 
farming pioneer, Bangkok). Farmers in an organic farming community near Chennai find happiness in rural living, their mutual support and social gatherings; in urban Chennai, some urbanites enjoy their home gardens and homemade produce, and this was also my observation in weekly school gardening sessions with 10 to 14-year-old students.

Besides personal benefits, the social dimension in terms of the close interaction and social community that many farmers and urban gardeners are able to build up is important for their aspirations for personal well-being. Solidarity with rural farmers can also be conducive to perceived well-being, and leading a simple lifestyle allows some participants to have more time for others:

'if I don't follow a simple life, I will not have time, I will not have energy, I will not have money to spend for the others' (interview, agro-ecological farming expert, Bangkok).

The principle of care for others seems central to the local understanding of social interaction, and in the case of the organic movement in Bangkok, it can be ascertained that Buddhist philosophies play a role. Interviews touched on various principles from Buddhist philosophies, namely the practice of metta-a kind of service to society-abstinence from killing or harming any beings and the practicing of patience, empathy, and modesty. Doing service to society and finding a deeper meaning in life through mindfulness motivated participants to engage in the organic food scene. These included an architect and pop singer who resigned from his outgoing lifestyle and well-paid job in favor of urban farming, simple living, and social community, and a former company director of a successful food cannery who wanted an occupation that serves people's health better and so started to produce organically on his own farm, to which he invites urbanites to pass his knowledge on to.

The principle of care sometimes connects consumers and farmers in a bi-directional manner in both the Bangkok and Chennai case studies: urban consumers' solidarity with rural farmers through purchasing their organic produce, and thereby favoring their livelihoods, and at the same time, the organic farmers commonly conveying their wish to produce good food for others. Solidarity can also occur among farmers who assist each other in farm work and marketing, just as in the organic farming community near Chennai.

Thus, mindfulness and care were two principles found in the organic food movements that majorly shaped the understanding and attainment of alternative practices.

I registered this relationship between organic farming practice and spirituality in both case studies.

With reference to the Buddhist conception of nature, organic farming goes beyond mere method to embrace a philosophy of living through the cultivation of both plants and human beings. The farmer in this conception becomes the caretaker for the land and at the same time the provider of healthy food for people. Thai language also provides a linguistic relation between nature and farming: the term kaset thammachart-natural farming — is usually preferred over 'organic farming', kaset meaning 'farming' and thammachart meaning the 'law of nature'. In organic Buddhist farming, a parallel is drawn between the cultivation of intact soils and healthy humans, which mainstream agriculture does not attend to. Besides physical human health, it can bring spiritual health like 'higher happiness' and 'enlightenment' (interview, food safety expert, Bangkok). A more general, holistic health view is: 'Your body and universal is the same', and 'if you destroy the earth by putting chemical [ ... ] to the soil, the food that you take to [ ... ] [build] your muscle, your body, it's will be [harmed] by those chemical' (interview, holistic health expert, Bangkok).

Some of the Thai organic farmers in my case study implied in the Buddhist principle of no-harming rejected agro-chemicals, since insecticides and fertilizers destroy insects and microorganisms as well as harming the farm environment and ultimately the human consumer. The Buddhist community Santi Asoke is a notable example of this, and organic farming is self-evident in their rural centers. Farming there is considered the most reputable layperson's occupation, and the community members-volunteers-have an intrinsic motivation since organic farming responds to their spiritual beliefs. The group has been a pioneer in promoting organic farming through workshops, using the 'religious system to run the whole thing' (interview, seed-saving activist, northern Thailand), and they 
also provide organic produce from their rural centers to urbanites in Bangkok. Visiting one of their rural centers, one witnesses simplicity and spirituality—simple wooden houses with kitchen gardens, collective bathrooms, instructions for repair, and recycling. Many community members walk barefoot, wearing simple garments mended several times, and use bicycles to get around. Meditation is part of the daily routine, and six monks live in the community.

This reflects the tendency of local alternative practices to resonate with Buddhist principles, which in turn, influences the concept of self-reliance presented in Sections 4.1 and 4.2.

Similarly, in the case study in Chennai, participants equally link organic farming to spiritual practice, as 'everything in India is linked with spirituality' (interview, ecologist, Chennai). Spiritual practice is a part of daily routine: 'if you ask "are you spiritual?" to a farmer, he will probably tell you "no". It's in Indian practices' (interview, ecologist, Chennai).

In fact, natural resources become worshipped for their sacredness through specific rituals:

'Seed is sacred, land is sacred, water is sacred. Starting to do ploughing is sacred [ ... ] Starting to do harvesting is sacred. Harvesting is the start of the festival. Finishing the harvest is sacred, because when you finish your harvest, you do a ritual. [ ... ] And the first harvest is always given to the temple. For most of the farmers, even today' (interview, ecologist, Chennai).

A spiritual aspect of farming lies within human's relation to their natural environment and resources, such as the land or water, which require their cultivation and protection; the saving and reproduction of indigenous seeds means preserving biodiversity and cultural heritage at the same time.

Both examples demonstrate how spirituality merges with daily life practices, and particularly in alternative food practices through the organic farming approach and mindful lifestyles (see also [42] (pp. 61-66)). This hints at the embeddedness of alternative practices in the local culture and spirituality, thus their particularity in the Thai and Indian settings. It notably demonstrates how cultural values such as mindfulness intertwine with sustainable farming principles and general sustainability notions.

\section{Discussion}

The insights from the case studies help with reflections about the local notions of alternative food practices in Bangkok and Chennai. With reference to Batat et al.'s definition [15], the ideologies and local notions characteristic to their regional settings shape these practices, going beyond a material, production-oriented angle [5]. In a discourse that largely is based on assumptions deriving from Western economies and morals, the case studies offer insights into alternative practices as grown inherently. As a complement to a holistic view of practices, they capture stakeholder motivations to engagement in organic food movements; further, notions of sustainability and embeddedness in local values of these. In the sustainability realm, these local notions that entail agricultural diversity and mindfulness can model for more sustainable food systems globally.

It was stated in both case studies that traditional practices are essentially organic and widely self-reliant. Although fading in some areas, especially the urban context, those practices are generally still available. Recollection of continuous practice contradicts the common discourse that tends to consider alternative practices for innovation, such as alternative food networks, to be 'new forms of relationships and governance' [6] (p. 376). This focus of innovation might relate to the reality that alternative practices in Western regions often derive from established market economies in contrast to those in Global South regions, based on which the agricultural settings regionally differ.

At the same time, modern agriculture is increasingly made responsible for an agricultural and public health crisis, and some farmers consequently switch to organic farming. To highlight, many farmers who 'cultivate chemical produce for the market [ ... ] have smaller plots where they cultivate organically for their home use' (interview, trustee of a foundation for indigenous knowledge, Chennai). Importantly, impulse is inherent and thus emerges from within the Thai or south Indian society itself. To take up Castells' [22] point (cf. Section 2), stakeholders in the movement seek alternatives 
to 'make sense of their lives [ ... ] because of needs and because of values: It is in the unfavorable socio-political setting of the agricultural and health crisis in combination with passive policies and capitalist consumption systems that alternative food and farming practices emerge as counter-practices. In both cases, they are marked by the insecurity of farmers' livelihoods.

The urge for healthy foods, with regard to the public health crisis, has achieved prominence more recently: respondents quoted as influencing factors for their engagement in the organic scene the 'exposure to contaminated foods and pollution [ ... ], proceeding illness, allergies to food additives [ ... ], stressful lifestyle, depression, loneliness in the city [ ... ], prominent capitalism, and unhealthy society' [39] (p. 205).

Nonetheless, the food practices of households in Bangkok and Chennai, compared to those in the 'Western' setting, have departed less from the traditional diets which were noted as nutritional and healthy by common sense. One reason certainly is a consistency in the popularity of their regional cuisines using local ingredients that exist alongside globalized food trends. The lifestyle shift towards more globalized lifestyles began rather recently and therefore helped maintain traditional practices up to the present. A similar situation exists for farming practices and lifestyles in general.

Regarding values in alternative food practices, both movements fulfil what Castells [22] names 'self-management; agricultural networks; helping each other simply in terms of wanting to be together' through more value-based relationships. Interestingly, as another insight, care for one's environment, including care for other beings in general, is within the local knowledge or moral systems and is set into practice. This hints at a holistic approach to sustainability. As an interview participant explains, a justice aspect lies in sustainable farming that relates to care: The 'chemical farming, [ ... ] this is the problem of the justice [ ... ] for farmer' and for 'the environment or other kind of living' (interview, food safety expert, Bangkok).

Mindfulness and spirituality are attributes of such a holistic approach and may be the local fashion of counter-consumerism and an alternative lifestyle. Mindfulness in the Thai case relates back to Buddhist philosophies and engaging in alternative food practices, hence this means for some to act according to moral principles. This concerns both alternative living and concrete organic farming methods. In the Indian case, it is especially the sacredness of resources such as land, water, and seeds that gives traditional farming a spiritual note and reflects prevalent human-nature bonds. These bonds were found particularly distinct among farmers who actively engaged in farm work, while non-farming farm owners tended to relate to their land in a more distant way. It may be assumed that the farmers' bonds with nature are not only socio-cultural, but also stem from the microbiological integrity of body and soil.

Some stakeholders become unintentional change makers in opposing the mainstream because their alternative practices integrate organically into their daily routines. This internalization might point to natural commitment to the movement beyond mere trend as a base for alternative practices; further, it might eventually result in sustainment of engagement, which the two case studies by groups of dedicated pioneers carrying the movement over decades reflect. The 'role of embodied practices' can help 'understand consumer involvement with [alternative food networks]' [5] (p. 9). Commitment, enhanced through spiritual and moral motivation, may be inspiration to other alternative scenes. Apart from this, consumers become increasingly inclined towards organic foods.

The organic stakeholder projects their own sustainability notions, which ascribe to local culture, knowledge and morals, onto alternative food practices. My fieldwork discovered a range of organic farming approaches that derive from these notions. To a great extent, these 'traditional farming' approaches are perceived as 'local wisdom' (interview, organic urban gardening expert, Bangkok) and had already been widely applied before the green revolution industrialized agriculture. They largely rely on farm-internal inputs instead of unrenewable fossil resources, and practice careful natural resource management, sometimes agroforestry, and mixed cropping, allowing for continuous harvest, and thus, income. 
Although local knowledge is there, as a participant explained, today's situation is precarious because of a widening knowledge gap. This participant regrets that academic curricula now favor theoretical knowledge on industrial farming and farm management, and internships are rarely with practitioners of local sustainable farming methods. The alternative food practices discourse could help strengthen curricula through courses on this local knowledge, including agricultural diversity within the agricultural universities. In the light of climate change in particular, locally adapted farming strategies are needed, and many farmers' practices in the case studies have proven validity. Traditional knowledge can provide long-term experiences obtained from practitioners, and thereby valid guidelines for the sustainable handling of natural resources. Although some universities in the study areas acknowledged and included organic farming approaches in their teaching, mainstream farming still dominates their curricula. A great part of this hesitation sources from a lack of recognition of positive results.

Since-as insights from my case studies show-the agricultural departments in Thailand and South India favor the agrochemical approach, organic farming policies are on paper but rarely brought into being. This is why support for organic farming mostly comes from grassroots NGOs, individuals, and the independent consumer-producer interface. Further, comprehensive research on alternative food practices may make those scenes more confident in bringing organic food matters further onto the policy agenda.

\section{Conclusions}

The analysis elaborated specificities of alternative food practices within the organic food movements in Bangkok and Chennai with the help of three themes: continuity and re-emergence; local notions of sustainability; and the embracing of mindfulness and spirituality as motivations.

The results, namely the non-newness and local notions of alternative practice, demonstrate the potential of alternative food movements in the Global South through several aspects: first, they justify the establishment of alternative food movements in the Global South. Second, they thereby call for reception and recognition by the, thus far, hegemonic 'Western' discourse, and for general empathy for the plurality of alternative practice approaches. Third, they provide an opportunity for mutual learning from the plurality of case studies. Fourth, the case studies may initiate the revival of traditional practices, assuming that these exist and are retrievable in those spheres where capitalist structures have been embedded. With regard to the Special Issue theme, the local farming practices often implement agricultural diversity, and in combination with modern techniques, they can naturally contribute to sustainable agriculture: Practitioners in the case studies appreciated the collocation of a variety of seasonal crops in alternation, the use of heirloom seeds adapted to the local environments, the organic, preferably farm-internal inputs, and a manageable scale for their resource efficiency as well as ecological and personal livelihood and health benefits.

The case studies presented alternative practices that were very specific to their local contexts, and stakeholders generating their own notions of sustainability. The latter were partly grounded in continuous local knowledge, and were sometimes adapted to the contemporary needs and local routines, philosophies, and ways of living. The embracing of mindfulness, including simplicity and spirituality, is integral.

The outlined specific qualities of the two case studies may contribute to the alternative practice discourse by introducing new perspectives on stakeholders' motivations to engage in alternative practices and on value-based ways of realizing those in adaptation to the local contexts. They can engender the opening of the common discourse for a more holistic approach and consideration of ethnographic elements in its theorization.

I therefore suggest that the alternative practice discourse should focus its conceptualization, to a greater extent, on cultural-spiritual traits in practices, as well as paying more attention to the individual stakeholder in complement with the prevailing production orientated angle, in order to fulfil the intention to move onto a higher level of global impact. 
Funding: My postdoctoral research at IITM, Chennai, India was funded by the Indo-German Centre for Sustainability (IGCS) through a scholarship financed by the German Academic Exchange Service (DAAD). My fieldwork in Bangkok did not receive any external funding. I acknowledge financial support by Land Schleswig-Holstein within the funding programme Open Access Publikationsfonds to the manuscript.

Acknowledgments: I would like to thank Frauke Kraas for her supervision throughout my doctoral research, and Sudhir Chella Rajan for his supervision of my postdoctoral research. Further, I would like to thank Stephanie Leder for her advice during the drafting of this paper. I am grateful to Florian Dünckmann, Athanasios Vafeidis, Jana Kühl, and Anna Lena Bercht for their comments, and Anna Read for her text editing. In addition, I would like to express particular thanks to the Magic Beans for letting me join their school gardening team, and to all my study participants in Bangkok and Chennai for sharing their experiences.

Conflicts of Interest: The author declares no conflicts of interest. The funders had no role in the design of the study; in the collection, analyses, or interpretation of data; in the writing of the manuscript, or in the decision to publish the results.

\section{References}

1. Jones, A.; Murphy, J.T. Practice and Economic Geography. 2010. Geography Compass, 4 (4). Available online: http://openaccess.city.ac.uk/2596/ (accessed on 5 August 2018).

2. Abrahams, C.N. Globally Useful Conceptions of Alternative Food Networks in the Developing South: The Case of Johannesburg's Urban Food Supply System; ERA: Edinburgh, UK, 2006; Available online: https://core.ac.uk/ download/pdf/277365.pdf (accessed on 17 December 2018).

3. Blumberg, R. Alternative food networks and farmer livelihoods: A spatializing livelihoods perspective. Geoforum 2018, 88, 161-173. [CrossRef]

4. Freidberg, S.; Goldstein, L. Alternative food in the global south: Reflections on a direct marketing initiative in Kenya. J. Rural Stud. 2011, 27, 24-34. [CrossRef]

5. Maye, D.; Kirwan, J. Alternative food networks. Sociopedia ISA 2010, 1-12. [CrossRef]

6. Sánchez Hernández, J.L. Alternative Food Networks: Concept, Typology, and Adaptation to the Spanish Context. Boletín Asoc. Geógrafos Españoles 2009, 49, 375-380.

7. Whatmore, S.; Stassart, P.; Renting, H. What's Alternative about Alternative Food Networks? Environ. Plan. A 2003, 35, 389-391. [CrossRef]

8. Maye, D. Moving Alternative Food Networks beyond the Niche. Int. J. Sociol. Agric. Food 2013, 20, $383-389$.

9. Anguelovski, I. Alternative food provision conflicts in cities: Contesting food privilege, injustice, and whiteness in Jamaica Plain, Boston. Geoforum 2015, 58, 184-194. [CrossRef]

10. Guthman, J. Bringing good food to others: Investigating the subjects of alternative food practice. Cult. Geogr. 2008, 15, 431-447. [CrossRef]

11. Slocum, R. Whiteness, space and alternative food practice. Geoforum 2007, 38, 520-533. [CrossRef]

12. Renting, H.; Marsden, T.K.; Banks, J. Understanding Alternative Food Networks: Exploring the Role of Short Food Supply Chains in Rural Development. Environ. Plan. A 2003, 35, 393-411. [CrossRef]

13. Goodman, D.; DuPuis, M.E.; Goodman, M.K. Alternative Food Networks, Knowledge, Practice, and Politics; Routledge: Abingdon, UK, 2012.

14. Kasser, T. Psychological Need Satisfaction, Personal Well-Being, and Ecological Sustainability. Ecopsychology 2009, 1, 175-180. [CrossRef]

15. Batat, W.; Manna, V.; Ulusoy, E.; Peter, P.C.; Ulusoy, E.; Vicdan, H.; Hong, S. New paths in researching "alternative" consumption and well-being in marketing: Alternative food consumption/Alternative food consumption: What is "alternative"? Rethinking "literacy" in the adoption of AFC/Social class dynamics in AFC. Mark. Theory 2016, 16, 561. [CrossRef]

16. Alatas, S.F. The Definition and Types of Alternative Discourses, Unknown. Available online: http://www.ios. sinica.edu.tw/cna/download/5b_Alatas_2.pdf (accessed on 19 August 2018).

17. Bell, D.; Valentine, G. Consuming Geographies, We are Where We Eat; Routledge: London, UK, 1997; ISBN 0-415-13767-5.

18. Pratt, J.; Luetchford, P.; Pratt, J.C.; Luetchford, P. Food for Change, The Politics and Values of Social Movements; PlutoPress: London, UK, 2014; ISBN 9780745334486.

19. Gibson-Graham, J.K. Diverse economies: Performative practices for 'other worlds'. Prog. Hum. Geogr. 2008, 32, 613-632. [CrossRef] 
20. Goodman, D.; Goodman, M.K. Alternative Food Networks. In International Encyclopedia of Human Geography; Kitchin, R., Thrift, N., Eds.; Elsevier: Amsterdam, The Netherlands, 2009; pp. 1-13.

21. Hillebrand, S.; Zademach, H.-M. Alternative Economies and Spaces: Introductory Remarks. In Alternative Economies and Spaces: New Perspectives for a Sustainable Economy; Zademach, H.-M., Hillebrand, S., Eds.; Transcript Verlag: Bielefeld, Germany, 2013; pp. 9-22. ISBN 978-3-8376-2498-4.

22. Mason, P. Viewpoint: Manuell Castells on the Rise of Alternative Economic Cultures. 2012. Available online: https://www.bbc.co.uk/programmes/b006r4vz (accessed on 1 August 2018).

23. Daya, S.; Authar, R. Self, others and objects in an 'alternative economy': Personal narratives from the Heiveld Rooibos Cooperative. Geoforum 2012, 43, 885-893. [CrossRef]

24. Sassatelli, R. The political morality of food: Discourses, contestation and alternative consumption. In Qualities of Food, 1st ed.; Harvey, M., McMeekin, A., Warde, A., Eds.; Manchester University Press: Manchester, NY, USA, 2004.

25. Mazrui, A.A. Foreword: The Seven Biases of Eurocentrism: A Diagnostic Introduction. In The Challenge of Eurocentrism; Kanth, R.K., Ed.; Palgrave Macmillan US: New York, NY, USA, 2009; pp. xi-xix.

26. Sharp, J.P. Geographies of Postcolonialism, Spaces of Power and Representation; Sage: Los Angeles, CA, USA; London, UK; New Delhi, India; Singapore; Washington, DC, USA, 2009.

27. Said, E.W. Orientalismus, 5th ed.; Auflage S. Fischer: Frankfurt am Main, Germany, 2017; ISBN 978-3-10-071008-6.

28. McGee, T.G. Western Geography and the Third World. Am. Behav. Sci. 1978, 22, 93-114. [CrossRef]

29. Flick, U. (Ed.) An Introduction to Qualitative Research; Sage: Los Angeles, CA, USA; London, UK; New Delhi, India; Singapore; Washington, DC, USA, 2014.

30. Mayring, P. Einführung in Die Qualitative Sozialforschung, Eine Anleitung zu Qualitativem Denken; Beltz Verlag: Weinheim, Germany; Basel, Switzerland, 2002.

31. Cupchik, G. Constructivist Realism: An Ontology That Encompasses Positivist and Constructivist Approaches to the Social Sciences. FQS Forum Qual. Soz. 2001, 2, 7.

32. Buechler, S.M. New Social Movement Theories. Sociol. Q. 1995, 36, 441-464. [CrossRef]

33. Giddens, A.; Sutton, P.W. Essential Concepts in Sociology; Polity: Cambridge, UK, 2014; ISBN 978-0-7456-4985-6.

34. Melucci, A. The Process of Collective Identity, Chapter 3. In Social Movements and Culture, Social Movements, Protest, and Contention; Johnston, H., Klandermanns, B., Eds.; University of Minnesota Press: Minneapolis, MN, USA, 1995; pp. 41-63.

35. Scott, A. Ideology and the New Social Movements; Unwin Hyman: London, UK, 1990.

36. Thornberg, R. Informed Grounded Theory. Scand. J. Educ. Res. 2012, 56, 243-259. [CrossRef]

37. Thornberg, R.; Charmaz, K. Grounded Theory. In Qualitative Research: An Introduction to Methods and Designs, 1st ed.; Lapan, S.D., Quartaroli, M.T., Riemer, F.J., Eds.; Jossey-Bass: San Francisco, CA, USA, 2012; pp. 41-68. ISBN 978-0-470-54800-4.

38. Balasubramanian, A.V.; A Hand to the Plough. We Need an Alternative Approach to Farming that Builds on Indigenous Knowledge and Resources. Available online: http://archives.mydigitalfc.com/indian-knowledgeseries/hand-plough-378 (accessed on 5 December 2017).

39. Bopp, J. New Momentum to Bangkok's Organic Food Movement: Interspersed Scenes Led by Mindful Pioneers. Ph.D Thesis, University of Cologne, Cologne, Germany, 2016.

40. National Economic and Social Development Board. Thailand's Social Development in Q4/2013 and the Year 2013, Bangkok. 2013. Available online: http://www.nesdb.go.th/nesdb_en/main.php?filename=social_dev_ report (accessed on 2 April 2016).

41. Thaitakoo, D.; McGrath, B.; Srithanyarat, S.; Palopakon, Y. Bangkok: The Ecology and Design of an Aqua-City. In Resilience in Ecology and Urban; Pickett, S.T.A., Cadenasso, M.L., McGrath, B., Eds.; Springer: New York, NY, USA, 2013; pp. 427-442.

42. Falvey, L. Sustainability: Elusive or Illusion? Wise Environmental Intervention; The Institute for International Development: Adelaide, Australia, 2004.

(C) 2020 by the author. Licensee MDPI, Basel, Switzerland. This article is an open access article distributed under the terms and conditions of the Creative Commons Attribution (CC BY) license (http://creativecommons.org/licenses/by/4.0/). 